\title{
Formas de tratamento no português brasileiro: a cortesia verbal no viés do ensino da língua materna
}

\author{
Izilene Leandro Silva ${ }^{\mathrm{i}}$
}

\begin{abstract}
RESUMO
O objetivo deste trabalho concentra-se em estudar a cortesia verbal como forma de tratamento, tendo como objeto de análise o romance A Moreninha, de Joaquim Manoel de Macedo. Os aportes teóricos que contribuíram para a pesquisa foram os trabalhos de Neves (2018), Fávero e Andrade (2015), Azeredo (2014), Cintra (1972), Bechara (2009), Biderman (1979) e Preti (2008). A metodologia selecionada para o desenvolvimento do artigo foi a pesquisa qualitativa e interpretativa das competências discursivas dos sujeitos inseridos no uso da língua. As análises mostraram que a maior dificuldade estrutural encontra-se no âmbito morfossintático, essencial para a construção dos enunciados, como também na deficiência semântica entre os pronomes de tratamento "você", "tu" e "vós", apresentados nos exemplos. Consideramos que as relações sociais apresentam de maneira significativa e singela as formas de tratamento expressas na interação, de acordo com o contexto de seus usos.
\end{abstract}

Palavras-chave: Formas de tratamento; Cortesia verbal; Ensino da Língua Portuguesa.

\begin{abstract}
This paper aims to study verbal politeness as a form of treatment, having as object of analysis the novel A Moreninha by Brazilian writer Joaquim Manoel de Macedo. As for the theoretical contributions to the research, we have the works by Neves (2018), Fávero and Andrade (2015), Azeredo (2014), Cintra (1972), Bechara (2009), Biderman (1979), and Preti (2008). The methodology selected for the development of this paper was the qualitative and interpretive research of the discursive competencies of the subjects inserted in the use of language. The analyses showed that the most significant structural difficulty is found in the morphosyntactic scope, which is essential for the construction of the utterances, as well as in the semantic deficiency between the treatment pronouns "você", "tu", "vós", presented in the examples. We believe that social relations present in a meaningful and straightforward way the forms of treatment expressed in the interaction, according to the context of their uses.
\end{abstract}

Keywords: Treatment methods; Verbal politeness; Portuguese Language Teaching.

\footnotetext{
${ }^{i}$ Doutoranda em Língua Portuguesa na Universidade do Estado do Rio de Janeiro (UERJ). É professora efetiva da Educação Básica da Secretaria de Educação do Estado de Mato Grosso (SEDUC-MT). ORCID: https://orcid.org/0000-0002-8913-8684 | izileneleandro@ yahoo.com.br
} 


\section{INTRODUÇÃO}

O processo comunicativo entre falantes de uma língua é estabelecido pela interação social e permeado pelas práticas linguísticas, de acordo com a intenção do locutor. Nesse viés, para entendermos o que as formas de tratamento podem revelar diante de certas hierarquias e determinado poder no contexto de seu uso, torna-se imprescindível entendermos o papel que irão desempenhar na interação social entre os falantes de uma língua no momento da comunicação oral ou escrita.

Segundo Azeredo (2014), a língua e a interação social são as principais razões de ser de uma pessoa, formas pelas quais ela reage, sente, imagina, sonha etc.; é uma experiência individual e única. De acordo com o autor, o fato de a língua ser um bem coletivo faz com que ela transmita as experiências de um falante na integralidade e na complexidade com seu interlocutor, pois, neste contexto, é preciso reorganizá-la nos termos de um código de representação e de comunicação entre os falantes da língua.

Conforme esclarece Valente (1999, p. 8), “o estudo da língua não pode estar desvinculado da realidade da vida e da organização comunitária", pois é preciso evidenciar uma diversidade de discursos - sejam verbais, sejam não verbais, na forma escrita ou oral, literários ou não literários, como os textos de ordem jornalística, linguagem publicitária, letras de música, cartuns etc. Neste processo, o papel do professor é primordial para inserir em suas aulas de língua portuguesa tal diversidade de textos e estudá-los com seus alunos.

Por outro lado, em A Gramática do português revelada em textos, Neves (2018, p. 22) afirma o valor do "estudo da gramática ancorado na reflexão sobre a linguagem a partir de textos". Sobre a presença dos textos literários, a autora "propõe [...] não perder a oportunidade de, pela reflexão, penetrar muito particularmente na composição de sentidos e efeitos nesses textos", visto que na literatura não há limite para a produção de textos literários, a não ser o alcance da expressão plena pela linguagem. Pela literatura, percebemos que cada escritor tem seu próprio estilo, explorando livremente e com muita criatividade todas as possibilidades que a gramática da língua lhe oferece.

Ainda segundo Neves (2018), o texto literário descreve discursos que certa comunidade considera como um padrão esperado para os usos linguísticos, e a literatura singulariza-se exatamente no sentido de não possuir outras pressões que não a plenitude 
da expressão pela linguagem, em função de critérios sociais e históricos, pelo que um texto não nasce necessariamente literário e muito menos canônico. Portanto, o poeta é quem explora mais livre ou criativamente "todas as possibilidades da gramática da língua" (NEVES, 2018, p. 22).

Essa especificidade do texto literário justifica seu abrigo especial na reflexão sobre os usos, sem deixar de mencionar as exemplificações que os autores utilizam em suas vastas obras gramaticais. Assim, justifica-se a escolha do romance A moreninha, obra da fase do Romantismo da literatura brasileira para compor as exemplificações no tratamento da cortesia verbal para o ensino da língua materna.

Azeredo (2014) comenta formas de tratamento utilizadas como expressões que o interlocutor utiliza ao interagir socialmente com outros falantes, apresentando diversas formas de se dirigir a eles, seja pela relação social, seja pela afetiva. Segundo o autor, o enunciador normalmente apresenta o primeiro caminho para que a linguagem aconteça, como nos exemplos Prezado cliente e Senhores e senhoras. Tais expressões são usadas somente como vocativos direcionados a um determinado público, indiferentemente. Ainda conforme Azeredo (2014, p. 14), em outros momentos, "o enunciador identifica o perfil social do interlocutor e o individualiza", tais como doutor, colega, professor etc.

Fávero e Andrade (2015) apontam que a palavra “cortesia” é compreendida como um conjunto de normas que a sociedade estabelece para regular o comportamento mais indicado para seus grupos no momento em que estão interagindo uns com os outros. As atitudes das pessoas devem ser ajustadas as essas normas preestabelecidas para os grupos de cada comunidade.

Com base nos autores supracitados, acreditamos que cortesia ${ }^{1}$, como forma de tratamento, são expressões que mantêm a capacidade do interlocutor de interagir com seu falante para fins de conhecimento das normas e suas funções no ensino da língua, tanto na forma oral quanto na forma escrita, observando sempre os diversos contextos sociais, culturais e históricos.

Portanto, a finalidade deste trabalho é estudar a cortesia verbal como forma de tratamento, tendo como objeto de análise o romance de Joaquim Manoel de Macedo $A$ Moreninha, cuja relevância encontra-se em mostrar a necessidade de se refletir sobre o tratamento que preconizamos da oralidade e da escrita no ensino de língua portuguesa, 
para mostrar aos alunos dos Ensinos Fundamental e Médio a importância de saber usar adequadamente a forma cortês nos diferentes meios sociais.

\section{O CONTEXTO HISTÓRICO-CULTURAL DAS FORMAS DE TRATAMENTO NO PORTUGUÊS BRASILEIRO}

Desde a era colonial, o ensino da língua portuguesa vem se destacando no mundo dos estudos linguísticos, tornando-se essencial para a interação e a comunicação entre os falantes de uma determinada comunidade linguística. Nesse viés, pesquisas apontam que as formas de tratamento na língua, doravante Português Brasileiro (PB), mostraram uma evolução comparada ao sistema descritivo dos tratamentos do Português Europeu (PE).

Em suas pesquisas, os autores Brown e Gilman (1960) demonstram que, no decorrer de muito tempo, houve modificações na estrutura da sociedade medieval europeia relacionadas ao crescimento das formas de tratamento - principalmente com a elevação da burguesia, determinando, assim, uma relação equitativa de poder. Desse modo, novos encadeamentos configuraram-se no processo do sistema pronominal e no latim. Esse sistema é formado por dois métodos de referência ao interlocutor, como nos exemplos: o pronome tu para indicar o singular, e o uos como fator de uso do plural.

Considerando-se o contexto histórico do advento da Revolução Francesa, o pronome de tratamento tu ganhou destaque, com a intenção de ter como lema suas concepções de igualdade na sociedade. Entretanto, as formas de tratamento vous e tu continuavam sendo utilizadas pela comunidade falante. Dessa maneira, é possível afirmar que a pesquisa de Brown e Gilman (1960) manifesta que o pronome $t u$ ampliou-se por meio do pronome vous, em razão da solidariedade entre as pessoas que perpassa o arcaísmo, anteriormente dominado pelas relações de poder de uma elite predominante.

Ainda segundo os pesquisadores, ainda no século IV, houve uma mudança com relação ao uos, que passa a ser empregado de uma forma singular, iniciando um tratamento respeitoso/cortês direcionado exclusivamente ao imperador romano. Já no final do século XIV, a burguesia começa a competir com a nobreza, formando, assim, uma nova sociedade aristocrata.

É pertinente destacar que, na Idade Média, principalmente no latim, já havia as formas nominais de tratamento, Maiestra/vestra e Excellentia/vestra. Todavia, somente 
algum tempo depois, as referidas expressões ganharam destaque nas línguas românicas. Em sua pesquisa, Cintra (1972) explica que, no ano de 1331, constatava-se a existência do tratamento Vossa Mercê. Em 1460, tal expressão de tratamento passou a ser utilizada exclusivamente em referência ao rei. No entanto, aproximadamente em 1490, ela tornouse insignificante, devido ao excesso de uso. Os pesquisadores Lopes e Duarte (2002) revelam que Vossa Mercê, progressivamente, passou a ocorrer como menção a outras comunidades aristocratas.

Cintra (1972) expõe de uma maneira histórica o avanço que ocasionou as formas de tratamento do PE, para pontuar que o sistema de inferência ao interlocutor $t u / v o ́ s ~ t e v e$ origem no latim. Essas formas de tratamento nominal não foram observadas nas escrituras dos séculos XIII e XIV, mostrando diferenças por meio da oposição entre o tu singular e o vós plural na relação de tratamento entre os interlocutores.

Outras formas de tratamento que valem a pena destacar são aquelas exclusivas da linguagem escrita, diferentemente de uso da forma na linguagem oral. Nos exemplos Exmo.; Sr. Dr., Exmo. Sr., tais expressões entram em desuso na língua oral a partir do século XX no Brasil e em Portugal, ainda que ainda circulassem com limitações. Em trabalho intitulado "Formas de Tratamento e Estruturas Sociais" (1973), Biderman investigou o problema das formas de tratamento. Nesse estudo, a autora fez uma relação dessas formas com as estruturas sociais nas sociedades latinas, principalmente na Península Ibérica e na América Latina.

Biderman (1973) informa que, na metade do século XIX, "circunscreve-se" a maneira como são tratados alguns grupos sociais e apresenta três formas nominais de tratamento, do superior ao inferior, como se segue: i) critério de idade (pais a filhos, tios a sobrinhos); ii) de posição social (magistrado a cidadãos comuns, professor a aluno); iii) iguais não íntimos, ou de relação assimétrica (homem e mulher, quando primos). Dessa maneira, algumas obras de escritores da literatura brasileira, como Machado de Assis, Manoel Antônio de Almeida, Martins Pena e Joaquim Manuel de Macedo, são referências para exemplificar a forma de tratamento dos personagens de seus trabalhos.

Conforme explica Cintra (1972, p. 46), o pronome vós é considerado uma forma de tratamento cortês universal e única, pronta para ser usada em qualquer situação de comunicação, mesmo naquelas direcionadas ao tratamento com reis. $\mathrm{O}$ autor enfatiza que tal tratamento permaneceu em Portugal somente até no início do século XV. A partir 
desse período, manifestaram-se outras expressões nominais para se referirem ao rei, aos fidalgos e, por último, a qualquer outra pessoa da sociedade.

Em relação à segunda metade do século XVIII em diante, Cintra (1972) explica que a forma de tratamento vós caiu em desuso e em seu lugar iniciou-se o uso do pronome você. Já no final do século XIX e o início do XX, a forma de tratamento na sociedade brasileira foi substituída de $t u$ para você no tratamento com pessoas íntimas, sejam familiares ou amigos. Machado de Assis, de forma geral, apresenta em seus textos exemplos dessas formas linguísticas, sendo que, até os anos 1870, o autor utilizava a forma $t u$ nas relações entre pessoas mais íntimas e, no início do século $\mathrm{XX}$, apresenta unicamente a forma você, inclusive no tratamento com seus amigos. Pesquisas apontam que o pronome oblíquo te e os pronomes possessivos teu, tua etc. de segunda pessoa caíram em desuso em quase todo o Brasil já no século XX, e o tratamento da terceira pessoa você permanece em evidência. É importante enfatizar que, nas comunidades do Rio Grande do Sul, o uso do pronome tu é vigente, com o acompanhamento das formas verbais da terceira pessoa.

Dessa forma, Cintra (1972) destaca que, a partir desse período, abrem-se espaços para expansão de outras formas substantivas relacionadas ao verbo para a terceira pessoa: o senhor, a senhora, o senhor doutor, o senhor diretor, o senhor ministro, o senhor presidente. Assim, os termos ligados a essas formas nominais de tratamento de cortesia estão conectados a uma sociedade de grupos distintos que apoiaram o emprego inicial dessas formas de tratamento cortês conduzidas pelo verbo da terceira pessoa, favorecendo uma linha mais simples e, ao mesmo tempo, complexa, principalmente no campo da gramática portuguesa, na qual a flexão verbal possibilita apresentar formas ricas e distintas.

\section{A LINGUAGEM DA CORTESIA VERBAL NO CONTEXTO DE ENSINO DE LÍNGUA PORTUGUESA}

O ensino de língua portuguesa, especialmente a gramática, é um campo de estudo complexo e amplo que requer delimitação para um trabalho rico e eficaz para o domínio da comunicação e da interação nas formas de tratamento. Dessa forma, priorizamos um estudo acerca da cortesia verbal no sentido de polidez, porque procuramos destacar a 
importância das relações sociais e culturais que ocorrem em uma determinada comunidade de língua. Acreditamos que o sucesso da comunicação e das interações sociais está ligado às formas como esses grupos relacionam-se em seus diferentes meios e, especialmente, à maneira como utilizam a cortesia verbal na comunicação. Nesse processo, são primordiais o papel do professor no contexto de ensino e as intenções do falante da língua, pois é impossível garantir uma abordagem pedagógica satisfatória da cortesia verbal sem que o professor crie métodos de trabalhos com materiais didáticos diferenciados e variados para o contexto social de uso.

Nesse viés, a busca por descobertas no campo de estudos da língua é instigante para qualquer pesquisador da área. Para muitos teóricos, estudar língua portuguesa traz à tona a necessidade de rever e analisar várias teorias que dizem respeito à gramática, visto que esta não está desvinculada da vida cotidiana de uma sociedade letrada. De acordo com Pereira (2011, p. 9), “a língua portuguesa é reverenciada, tratada como estrela que é no universo em que se insere, sem medo de modismos ou rapapés superficiais e vazios". Concordamos com a autora, pois, neste processo, estudamos especificamente as formas de tratamento da cortesia verbal produzidas pela linguagem na interação social do falante da língua.

Bechara (2009) defende que a linguagem é uma atividade humana de falar; assim, o ato linguístico é o que concretiza a realidade da linguagem, estabelecendo a comunicação, seja por palavra ou por frase. Desse modo, é possível compreender as especificidades dos atos linguísticos em uso, pois, em referência a eles, o autor destaca que

[...] não se realizam idênticos de falante para falante de uma mesma comunidade linguística, e até num só falante, em circunstâncias diferentes. Essa diversidade não se dá somente na forma material do ato linguístico, isto é, na sua expressão, mas também no seu significado. (BECHARA, 2009, p. 18)

Segundo Pereira (2011, p. 9), não devemos apavorar-nos com novas correntes, teorias revolucionárias, ou "ideias X". Na perspectiva da autora, não se pode perder o foco sobre a língua materna em seus desdobramentos e suas possibilidades. Assim, é o professor de língua portuguesa que, ao atuar em sala de aula, tem diante de si duas possibilidades de ensinar o português: a partir de "modelos experimentais", ou por meio de "posturas tradicionais". 
Para Azeredo (2014), o conceito de gramática refere-se ao sistema de regras que permite aos falantes de uma língua construir e compreender suas frases. Segundo o autor, tais conceitos são técnicos e geralmente adotados pelos linguistas gerativistas para uma visão comparativa, de forma que "ninguém aprende a falar uma língua sem adquirir sua gramática. [...] Ela está presente no modo de pronunciar as palavras, na ordem em que estas ocorrem na frase" (AZEREDO, 2014, p. 33).

É importante esclarecer que o uso de uma língua em suas diferentes variações constrói-se a partir de algum significado, de maneira que os sujeitos falantes comunicamse porque as conhecem e empregam em todos os momentos de interação social. Assim, uma língua é um sistema abstrato reconhecível nos muitos usos, orais ou escritos, que seus falantes fazem dela. Os indivíduos concretizam esse sistema, seja como enunciadores, seja como destinatários, nas múltiplas situações de uso. Por isso, o uso da língua é, em princípio, um ato individual (AZEREDO, 2014).

O gramático aponta que o uso de uma língua deve estar de acordo com fatores sociais e históricos que passam a pertencer a todos que, de alguma forma, exercem-na em função de certa pressão padronizadora, que constitui uma norma do uso da língua por grupos sociais de uma mesma comunidade. Essa norma está relacionada ao "conjunto de realizações fonéticas, morfológicas, lexicais e sintáticas produzido e adotado mediante um acordo tácito pelos membros da comunidade" (AZEREDO, 2014. p. 63).

Vidal (1995) esclarece que é possível compreender-se a cortesia por meio de normas definidas por uma determinada sociedade para regular a maneira adequada de seus grupos, de modo que possa desfavorecer algumas formas de conduta, criando possibilidades favoráveis a outras. Segundo a autora, o que se enquadra nas regras pode ser considerado forma cortês, e o que não se enquadra, descortês.

Podemos entender que um dos pontos destacáveis da correlação entre cortesia e formas linguísticas são as formas de tratamento, sendo de enorme importância regulá-las de acordo com as normas sociais, refletindo-se sobre o contexto situacional das regras conversacionais de interesse e expectativas do que será dito segundo as convenções sociais. Nesse sentido, o impacto da forma cortês ou descortês decorrerá da permanência de uma regra cultural específica, referente ao conteúdo ou à forma do enunciado, considerando, desse modo, os conhecimentos comunicativos entre os interlocutores. 
Cintra (1972) declara como formas de cortesia aquelas consideradas na ordem formal. Entretanto, acreditamos que não se trata de ser formal ou informal, nem mesmo de regra que envolve o processo cortês ou descortês, mas do momento em que o indivíduo faz uso dessa forma de tratamento no seu contexto social. No Brasil, é possível perceber que o emprego do tratamento formal "a senhora" pode causar duplo sentido, como cortesia ou descortesia. Por exemplo, no contexto escolar, quando o aluno faz uso desse termo no momento de cumprimento, ele corre o risco de a professora acreditar que a considera uma senhora velha. Isso ocorre porque há muito tempo tal tratamento seria cortês e, nos dias atuais, pode ser considerado descortês, a depender da situação de uso e dos interlocutores envolvidos no processo interativo.

Nesse processo de interação social, entendemos ser oportuno inserir o ensino da cortesia verbal como forma de tratamento cortês nos diversos momentos situacionais dos falantes.

\section{O ENSINO DAS FORMAS DE TRATAMENTO POR MEIO DE GRAMÁTICAS NORMATIVAS}

Os estudos relacionados ao uso das normas ${ }^{2}$ gramaticais estão relacionados, segundo Bechara (2009, p. 28), à gramática normativa, que "recomenda como se deve falar e escrever segundo o uso e a autoridade dos escritores corretos e dos gramáticos e dicionaristas esclarecidos". Assim, é possível enfatizar as pesquisas direcionadas ao uso das formas de tratamento da língua, por meio de alguns teóricos especializados e renomados nas diferentes formas de legitimidade. Entre os principais gramáticos, contamos com Celso Cunha e Lindley Cintra (2017), Rocha Lima (2011), Bechara (2009), Cunha (1990).

As gramáticas normativas consolidaram-se a partir do século $\mathrm{XV}$, na esteira dos estudos gramaticais gregos e romanos que conceituaram a gramática como a arte do uso “correto" da língua. É nessa extensão histórica que tem origem o perfil das gramáticas das línguas europeias modernas. A esse respeito, Bechara argumenta que

[q]uando nos referimos à língua portuguesa, língua espanhola, língua alemã ou língua latina, fazemos alusão a uma língua como produto cultural histórico, constituída como unidade ideal, reconhecida pelos falantes nativos ou por 
falantes de outras línguas, e praticada por todas as comunidades integrantes desse domínio linguístico. Entendido assim, esse produto cultural recebe o nome de língua histórica. Esse amplo e diversificado espaço cultural, historicamente relacionado, está presente na frase de Fernando Pessoa: Minha pátria é a língua portuguesa. (BECHARA, 2009, p. 24)

Em nossa análise, partimos da perspectiva do gramático Henriques (2009, p. 12), que defende o uso da língua como um "treinamento, hábito, vontade... pensar metalinguisticamente, porque a descoberta do entendimento das coisas da língua é alimento do espírito, é inspiração para outras reflexões e descobertas". Segundo postulado pelo autor de Nomenclatura Gramatical Brasileira: 50 anos depois, tudo o que está ao nosso redor, o que fazemos, o que falamos, - ou seja, "um comentário aqui, um encaminhamento ali, vamos indo pelas beiradas em busca da confraternização linguísticogramatical, sem traumas nem rancores" (HENRIQUES, 2009, p. 12) - é gramática pura e em funcionamento. Henriques também defende que "não é preciso uma nomenclatura gramatical sofisticada. Só se pede que ela seja apenas uma”. Assim, para o autor, a NGB funciona como um instrumento que permite ao professor, ao pesquisador e ao estudante ter um direcionamento básico, singular no estudo da língua portuguesa.

Diante destas perspectivas, Lima (2011, p. 386) destaca que o pronome de tratamento você está relacionado com a segunda pessoa, concordando com o verbo na terceira pessoa, em razão da origem de vossa mercê. Essa concordância relaciona-se com o substantivo mercê para indicar o tratamento dado à reverência vossa majestade, vossa excelência etc. Dessa forma, o autor preconiza que é com os substantivos, e não com o pronome possessivo (vossa), que ocorre a concordância.

Bechara (2009), por sua vez, considera que a forma substantiva de tratamento indireto de segunda pessoa leva o verbo para a tercceira pessoa. Tal como outros gramáticos tradicionais, o autor nomeia essas formas como substantivas de tratamento ou pronominais de tratamento. Vejamos os seguintes exemplos: você, vocês (no tratamento familiar), o Senhor, a Senhora (no tratamento cerimonioso). Acrescenta o autor:

$1^{\text {a }) ~ E m p r e g a-s e ~ V o s s a ~ A l t e z a ~(e ~ d e m a i s) ~ q u a n d o ~} 2^{\mathrm{a}}$ pessoa, isto é, em relação a quem falamos; emprega-se Sua Alteza (e demais) quando $3^{\mathrm{a}}$ pessoa, isto é, em relação à de quem falamos.

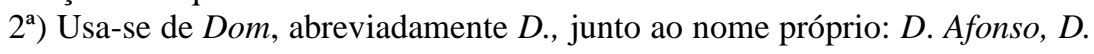
Henrique, D. Eugênio; às vezes aparece em autores junto a nome de família, mas esta prática deve ser evitada por contrariar a tradição da língua. Usa-se ainda $D$. junto a outro título: $D$. Prior, $D$. Abade, etc. 


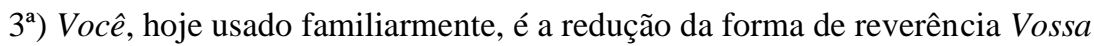
Mercê. Caindo o pronome vós em desuso, só usado nas orações e estilo solene, emprega-se vocês como o plural de $t u$.

$\left.4^{\mathrm{a}}\right) \mathrm{O}$ substantivo gente, precedido do artigo a e em referência a um grupo de pessoas em que se inclui a que fala, ou a esta sozinha, passa a pronome e se emprega fora da linguagem cerimoniosa. Em ambos os casos o verbo fica na $3^{\mathrm{a}}$ pessoa do singular: "É verdade que a gente, às vezes, tem cá as suas birras" [AH.4, II, 158].

$5^{\mathrm{a}}$ ) Ainda continuam vivos em Portugal vós, vosso. (BECHARA, 2009, p. 140)

O autor esclarece que é importante observar esses pronomes de tratamento relacionados às formas de reverência de um interlocutor quando se dirige às pessoas por suas virtudes, atributos e características sociais. É basilar destacar a expressão linguística como traços de polidez ou, ao contrário do convívio social, modéstia, nos quais pode o falante ou escritor inverter a ordem de referência ao seu interlocutor, seja representado por pronome, seja por substantivo, seja em práticas de cortesia entre franceses e espanhóis.

Bechara (2009) exemplifica um modo de cortesia com um excerto do romance $O$ Senhor do Paço de Ninães (1867), de Camilo Castelo Branco, identificada na seguinte preferência do autor: "Estamos no Minho, o leitor e eu" (apud BECHARA, 2009, p. 147). Segundo o gramático, a cortesia linguística não se detém na regra dos pronomes; pelo contrário, invade o domínio da concordância, como a realizou Rui Barbosa em conhecido trecho de uma carta: “[...] e S. Exc. a respondera, declarando aceitaria, sob a condição de anuírem o Barão do Rio Branco e eu” (BECHARA, 2009, p. 147). Em suma, o gramático explica que "a concordância gramatical, pela presença de pronome de primeira pessoa, exigiria o verbo flexionado na primeira do plural: anuirmos. Todavia, em razão da urbanidade, a polidez se reflete não só na ordem dos pronomes, mas ainda na flexão verbal" (BECHARA, 2009, p. 147).

\section{O SENHOR AUGUSTO E A SENHORA DONA CAROLINA DO ROMANCE A MORENINHA, DE JOAQUIM MANOEL DE MACEDO}

O corpus escolhido para a realização deste estudo é a obra de Joaquim Manoel de Macedo $^{3}$, A Moreninha, publicada em 1844. Trata-se do primeiro grande romance da literatura romântica brasileira, que alcançou enorme sucesso e garantiu grande prestígio 
ao autor. No século XIX, a cidade do Rio de Janeiro era a capital do Império, sendo a Corte conhecida como o lugar principal dos relacionamentos, representados por uma burguesia crescente. Era um período de muitas inovações e crescimento da cidade, que contava com uma classe dominante de burgueses. Nesse contexto, prevalecia nos relacionamentos o casamento por interesse, por conta dos dotes, porém o romance de Augusto e Carolina ilustra uma nova espeficidade de amor para o período.

Acreditamos que a referida obra retrata um romance proibido em tom jocoso, ganhando notoriedade e provocando grandes reviravoltas no momento final da história. Joaquim Manoel de Macedo inicia a obra apresentando a reunião de quatro amigos estudantes de Medicina que intencionam passar o feriado de Sant'Ana na "ilha de...", a pedido do amigo Filipe. O assunto na reunião dos jovens estudantes gira em torno das mulheres que possivelmente estarão na festa, e as prováveis paixões que poderiam surgir.

A história acontece em torno do personagem Augusto, que é apresentado como o mais inconsequente deles. Ele basicamente troca um romance por outro, ou seja, troca de namorada pelo menos uma vez por mês. Diante disso, Filipe faz uma aposta com Augusto: caso ele permanecesse apaixonado por mais de um mês pela mesma pessoa, deveria escrever uma história; em caso negativo, seria Filipe a escrever um romance.

Grande parte da história se passa na "ilha ${ }^{4}$ de..." e os amigos Filipe, Augusto, Fabrício e Leopoldo encontram-se com aproximadamente vinte pessoas, divertindo-se nesse pequeno grupo social, primordialmente com os olhos voltados às mulheres mais bonitas da festa - D. Carolina, Joaquina e Joana. Vale ressaltar que o ponto central da obra é o romance que nasce entre o personagem Augusto e D. Carolina, irmã de Filipe, uma menina levada de 13 anos.

[Augusto:] [...] [A]firmo, meus senhores, que meu pensamento nunca se осирои, não se осира, nem se há de ocupar de uma mesma moça quinze dias. [Filipe:] - Se perderes, escreverás a história de tua derrota, e se ganhares, escreverei o triunfo da tua inconstância.

- Por quem são!... deixem minha avó e tratemos da patuscada. Então tu vais, Augusto?

- Não.

- É uma bonita ilha.

- Não duvido.

- Reuniremos uma sociedade pouco numerosa, mas bem escolhida.

- Melhor para vocês.

- No domingo, à noite, teremos um baile.

- Estimo que se divirtam [...]. (MACEDO, 1844, p. 2, grifos nossos) 
Nesse pequeno exemplo, já podemos perceber o uso da forma de tratamento nominal meus senhores, na fala do personagem Augusto. Nota-se que o personagem dá ênfase ao verbo ocupar. Consideramos aqui uma forma cortês que ele e seus amigos utilizam, como no exemplo: "Se perderes, escreverás a história de tua derrota, e se ganhares, escreverei o triunfo da tua inconstância”. Os verbos perderes, escreverás, ganhares, escreverei, futuro do subjuntivo marcados com o condicional "se" foram usados no diálogo em referência ao que aconteceu no momento em que se fala.

- E demais, tornou Fabrício, palavra de honra que nenhum de nós tomará o trabalho de lá ir por causa da velha.

- Augusto, minha avó é a velha mais patusca do Rio de Janeiro

- Que me importa?... Deixe-me. Vocês sabem o meu fraco e caem-me logo com ele: moças!.. moças!... Confesso que dou o cavaco por elas, mas as moças me têm posto velho.

- É porque ele não conhece tuas primas, disse Fabrício.

- Ora... o que poderão ser senão demoninhas, como são todas as outras moças bonitas?

- Então tuas primas são gentis?... perguntou Leopoldo a Filipe.

- A mais velha, respondeu este, tem dezessete anos, chama-se Joana, tem cabelos negros, belos olhos da mesma cor, e é pálida. (MACEDO, 1844, p. 3, grifos nossos)

No exemplo 2, os diálogos transcritos são dos personagens Fabrício, Augusto, Leopoldo e Filipe. Observamos o uso da forma de tratamento de maneira informal, apresentando uma linguagem coloquial, uma das características do romance, indicando também proximidade, intimidade entre os participantes da história.

- Bem raciocinado... não tem dúvida, acudiu Filipe; então, conto contigo, Augusto?

- Dou-te palavra... e mesmo porque eu devo visitar tua avó.

- Sim... já sei... isso dirás tu a ela.

- Mas vocês não têm reparado que Fabrício tornou-se amuado e pensativo, desde que se falou nas primas de Filipe?...

- Disseram-me que ele anda enrabichado com minha prima Joaninha.

- A pálida?... pois eu já me vou dispondo a fazer meu pé-de- alfares com a loura.

- E tu, Augusto, quererás porventura reqüestar minha irmã?... (MACEDO, 1844 , p. 4 , grifos nossos)

No exemplo 3, os amigos conversam sobre a visita à casa da avó de Filipe e sobre como vão cortejar as moças na festa. O pronome contigo na primeira frase do diálogo refere-se ao amigo Augusto, assim como o verbo dou, juntamente com os pronomes te e $t u$, marcados pelo uso da segunda pessoa do singular, predominando os enunciados com 
os respectivos sujeitos no uso da língua. Sendo assim, a relação entre os elementos linguísticos empregados nas formas de pronomes pessoais é de heterogeneidade, explicitando o uso na língua corrente.

- O senhor está doido?! disse-me gemendo e fazendo uma careta horrível, o meu companheiro da esquerda.

- Não tenho que lhe dar satisfações, respondi-lhe amuado.

- Tem, sim senhor, retorquiu-me o sujeito, empinando-se.

- Pois que lhe fiz eu, então? acudi, alterando-me.

- Acaba de pisar-me, com a maior força, no melhor calo do meu pé direito.

- Ó senhor... queira perdoar!... (MACEDO, 1844, p. 7, grifos nossos)

Na primeira parte da fala dos personagens, no exemplo 4, encontramos o uso do pronome nominal senhor e companheiro, conforme apresentado no excerto acima - "O senhor está doido?! disse-me gemendo e fazendo uma careta horrível, o meu companheiro da esquerda". Nessa parte do enunciado, é importante enfatizar que se faz necessário o uso das formas substantivas na oração, produzindo uma marcação do interesse enunciativo com o intuito pragmático já anunciado. Em outro exemplo, percebemos o emprego dessas formas, assim como a tônica que produz este interesse: "Tu pertences àquelas senhoras que estão no camarote, a cuja porta te encostavas?”.

- Tobias, escravo de meu senhor, crioulo de qualidades, fiel como um cão e vivo como um gato. $\mathrm{O}$ maldito do crioulo era um clássico a falar português. $\mathrm{Eu}$ continuei.

- Hás de levar um recado à Sra. D. Joana.

- Pronto, lesto e agudo, respondeu-me o moleque.

- Pois toma sentido.

- Não precisa dizer duas vezes.

- Ouve. Das duas uma: ou poderás falar com ela hoje ou só amanhã...

- Hoje... agora mesmo. Nestas coisas Tobias não cochila: com licença de meu senhor, eu cá sou doutor nisto; meus parceiros me chamam orelha de cesto, pé de coelho e boca de taramela. [...] (MACEDO, 1844, p. 9, grifos nossos)

As relações de poder e hierarquia estabelecidas no excerto acima são marcadas pela fala do escravo (Tobias) e Meu senhor (Augusto), em que há tratamento de respeito entre ambos, pois o trato do escravo com seu senhor é perceptível no momento em que ele atende imediatamente o pedido de Augusto, usando o tratamento formal ao invés do tratamento informal. Portanto, o propósito comunicativo neste âmbito é dar ênfase à formalidade no tratamento entre os personagens do romance. 
As formas nominais de tratamento o senhor e a senhora são de praxe usadas primeiramente nas relações interpessoais entre pessoas mais velhas, com os pais, de funcionários de lojas com clientes, de pacientes com médicos, de empregados com patrões e, por último, de aluno com professor ou professora, quando aceita ser atendida por mera formalidade de respeito. No entanto, hoje não é incomum os jovens tratarem tanto seus pais quanto pessoas mais velhas por você. As famílias tradicionais costumam ensinar seus filhos a chamarem por senhor ou senhora em sinônimo de respeito, atenção, cordialidade, mantendo a tradição desse tratamento cortês.

Em suma, nas falas dos personagens do romance, predominou o uso da forma nominal senhor, senhora, com a forma verbal efetivamente distribuída nos respectivos diálogos entre eles. Percebemos a predominância da forma de tratamento cortês, já que se tratava de uma história do início do século XX. Sabemos que a cortesia verbal é um fenômeno cultural e social, no qual as relações estruturais sintáticas, morfológicas e fonológicas da língua estão em sintonia; o estudo não deve ficar somente em nível avançado, mas também ser levado para a sala de aula, desde o princípio da aprendizagem, em todos os níveis de ensino. Acreditamos que a contribuição desta pesquisa é apresentar aos docentes alternativas para trazer para seu plano de aula esses conteúdos indispensáveis ao ensino da língua materna.

\section{CONCLUSÃO}

Os estudos apontados acerca das formas de tratamento manifestaram que os aspectos de cortesia verbal são predominantes em qualquer situação de comunicação entre falantes de uma língua. As análises mostraram que a maior dificuldade estrutural encontra-se no âmbito morfossintático, este essencial para a construção dos enunciados, como também na deficiência semântica entre os pronomes de tratamento você, tu e vós, apresentados nos exemplos.

Através do estudo, foi possível observar também a interferência no uso das unidades do tratamento cortês na interação verbal dos falantes do português brasileiro, ao empregarem formalmente tais elementos. Dessa forma, acreditamos que o ensino e a aprendizagem de alguns elementos linguísticos não transitam unicamente pela estrutura formal, pois é preciso superar as interferências identificadas nos estudos da língua 
materna. No entanto, a estrutura gramatical é fundamental, principalmente no contexto da linguagem escrita, visto que precisamos utilizar os elementos linguísticos adequados a cada situação de uso, de acordo com o contexto. Compreendemos que todos esses motivos certificam que há heterogeneidade de uso da língua e, primordialmente, interação com os diversos meios, tanto sociais e culturais quanto históricos da linguagem.

\section{Referências}

AZEREDO, José Carlos de. Gramática Houaiss da Língua Portuguesa. São Paulo: Publifolha, 2014.

BECHARA, Evanildo. Moderna gramática portuguesa. $37^{\mathrm{a}}$ ed. rev., ampl. e atual. conforme o novo Acordo Ortográfico. Rio de Janeiro: Nova Fronteira, 2009.

BIDERMAN, Maria Tereza Camargo. Formas de Tratamento e Estruturas Sociais. ALFA, n. 18/19, 1972-1973, p. 339-382.

BROWN, Roger; GILMAN, Albert. The Pronouns of Power and Solidarity. In: SEBEOK, Thomas Albert. (Ed.). Style in Language. Massachusetts: Press of Massachusetts Institute of Technology, 1960. p. 252-276.

CINTRA, Luís Filipe Lindley. Sobre 'formas de tratamento' na língua portuguesa. Lisboa: Livros Horizonte, 1972.

CUNHA, Celso Ferreira da. Gramática da língua portuguesa. Rio de Janeiro: FAE, 1990.

CUNHA, Celso; CINTRA, Lindley. Nova gramática do português contemporâneo. $7^{\mathrm{a}}$. ed. Rio de Janeiro: Lexikon. 2017.

VIDAL, María Victoria. Cortesía, formulas convencionales y estrategias indirectas. Revista Española de Linguística, v. 25, n. 1, p. 31-66, 1995.

FÁVERO, Leonor Lopes; ANDRADE, Maria Lucia. Cortesia verbal e ensino de língua: reflexões sobre competência comunicativa, jogo interpessoal e normatividade. Filol. Linguíst. Port., São Paulo, v. 17, n. 1, p. 101-129, 2015.

HENRIQUES, Claudio Cesar. Nomenclatura gramatical brasileira: 50 anos depois. São Paulo: Parábola Editorial, 2009.

LIMA, Carlos Henrique da Rocha. Gramática normativa da língua portuguesa. $49^{\mathrm{a}}$ ed. Rio de Janeiro: José Olympio, 2011. 
LOPES, Célia. Vossa Mercê > você e Vuestra Merced > usted: o percurso evolutivo ibérico. LINGUÍSTICA, 14, p. 173-190, 2002.

MACEDO, Joaquim Manoel de. A Moreninha. São Paulo: Scipione, 1844.

NEVES, Maria Helena de Moura. A gramática do português revelada em textos. São Paulo: Editora Unesp, 2018.

PEREIRA, Maria Teresa Gonçalves. Prefácio. In: VALENTE, André C.; PEREIRA, Maria Teresa Gonçalves. (Org.). Língua Portuguesa: descrição e ensino. São Paulo: Parábola Editorial, 2011.

PRETI, Dino (Org.). Cortesia Verbal. São Paulo: Humanistas, 2008. 374 p. (Projetos Paralelos - NURC/SP; v. 9).

VALENTE, André (org.). Aulas de Português: perspectivas inovadoras. Petrópolis: Vozes, 1999.

Recebido em: 31/08/2021

Aceito em: 09/01/2022

\footnotetext{
${ }^{1}$ Fávero e Andrade (2015) definem "cortesia" como uma palavra polissêmica. As autoras justificam que são empregadas como sinônimo de polidez.

${ }^{2}$ Segundo Bechara (2009, p. 28), a norma contém tudo o que na língua não é funcional, mas que é tradicional, comum e constante, ou, em outras palavras, tudo o que se diz "assim, e não de outra maneira". É o plano de estruturação do saber idiomático que está mais próximo das realizações concretas. O sistema e a norma de uma língua funcional refletem a sua estrutura.

${ }^{3}$ Nasceu em 24 de junho de 1820, em São João do Itaboraí, Estado do Rio de Janeiro. Formado pela Faculdade de Medicina do Rio de Janeiro em 1844, logo após publicou o livro A Moreninha e pouco exercia a função de médico, dedicando-se ao jornalismo, à política, ao magistério e às letras. Também foi deputado em várias legislaturas.

${ }^{4} \mathrm{O}$ escritor não apresenta o nome da ilha, sempre se referindo ao lugar como "a ilha de ...”.
} 